\title{
R Wave Abnormality by ECG Finding
}

National Cancer Institute

\section{Source}

National Cancer Institute. R Wave Abnormality by ECG Finding. NCI Thesaurus. Code C90443.

An electrocardiographic finding of an atypical R wave within the QRS complex; it is due to a disturbance in the depolarization mechanism of the ventricular myocardium. 